\title{
Relations between structural characteristics, forest involvement, and forest knowledge among private forest owners in Sweden
}

\author{
Louise Eriksson ${ }^{1}\left[\right.$ Clas $^{2}$ Fries $^{2}$
}

Received: 23 September 2019 / Revised: 15 June 2020 / Accepted: 2 September 2020 / Published online: 15 September 2020

(c) The Author(s) 2020

\begin{abstract}
An understanding of private forest owners is needed for appropriate forest governance and outreach to forest owners. This study examined different types of objective and subjective knowledge (i.e., actual knowledge and confidence, respectively), including general forest knowledge and knowledge of management for different objectives, among individual private forest owners in Sweden. In addition, the importance of structural variables (e.g., gender, size of forest holding) and forest involvement variables (e.g., certification, involvement in forest planning) for forest knowledge was analysed. The study was conducted by means of a postal questionnaire to a random sample of private forest owners in Sweden $(n=3000$, response rate $43 \%$ ). Structural variables, but particularly involvement variables, were found to be related to subjective and objective knowledge. Being a male owner, owning a larger forest holding, having bought the land, and having owned the forest a long time were associated with higher subjective knowledge, or confidence, in managing the forest. Although being a male owner, for example, was also associated with higher levels of objective knowledge, the correlation diminished when controlling for forest involvement. The study considers the role of learning environments for forest owners and highlights the need to elaborate on the conceptualization and measurement of forest knowledge to understand the links between structural characteristics, forest involvement, and forest knowledge among private forest owners.
\end{abstract}

Keywords Learning environments $\cdot$ Private forest owners $\cdot$ Objective forest knowledge $\cdot$ Subjective forest knowledge

\section{Introduction}

The management of forests has implications on ecosystem services; that is, regulating, supporting, provisioning, and cultural services provided by the forest. Optimizing, for example, the provisioning of timber, may be detrimental to aspects such as biodiversity maintenance (Trivino et al. 2017). To combat climate change, the forest may be used for carbon sequestration via either forest management for

Communicated by Martin Moog.

Electronic supplementary material The online version of this article (https://doi.org/10.1007/s10342-020-01314-3) contains supplementary material, which is available to authorized users.

Louise Eriksson

louise.eriksson@umu.se

1 Department of Geography, Umeå University, 90187 Umeå, Sweden

2 Forest Unit, Swedish Forest Agency, Box 284, 90106 Umeå, Sweden biomass production (substitution) or increasing the standing volume of trees (storage). However, while substitution may threaten biodiversity, storage may impede production goals (Bellassen and Luyssaert 2014; Felton et al. 2016; Klapwijk et al. 2016; Peura et al. 2018). With growing demands to use the forest for different purposes as well as societal and environmental uncertainties related to the market for wood products, forest disturbances, and climate change, for example (Lindner et al. 2014; Seidl et al. 2014; Blanco et al. 2017), decisions regarding how to manage forests are highly complex. With a large share of privately owned forests in places like the US and several European countries (e.g., Sweden, Finland, and Germany), the management decisions of individual private forest owners (also labelled family forest owners) have a significant impact on the ecosystem services provided by forests. With a nuanced understanding of private forest owners, the governance of private forests, including forest policy and outreach, can be improved.

Historically, private forest owners were often also farmers, living close to their forest and depending on the forest as their main source of income. However, the sociodemographic 
profile of forest owners is changing (Hogl et al. 2005; Follo et al. 2016; Haugen et al. 2016; Ficko et al. 2017; Weiss et al. 2019). For example, the share of forest owners who are farmers is decreasing while the number of non-resident owners, female owners, and owners with a higher education is increasing. The diversity among forest owners is evident not only in sociodemographic characteristics but also in value orientations or forest values, forest owner objectives (e.g., emphasizing production or conservation goals), the intensity of management, and goods provided by the forest (e.g., Eriksson 2012; Põllumäe et al. 2014; Blanco et al. 2015; Ficko et al. 2017). Against the backdrop of these changes, concerns have been raised that more owners are becoming detached from the practical issues of the forest. It has been suggested that owners display less experience and knowledge of management, associated with perceiving a loss of control (Lähdesmäki and Matilainen 2014; Huff et al. 2017; Upton et al. 2019). In support of this reasoning, forest owner typologies generally identify a subgroup of owners labelled 'indifferent' or 'passive' (e.g., almost one-fifth of the owners in a Swedish study by Ingemarson et al. 2006; see also Ficko et al. 2017). However, despite these concerns, the level of forest knowledge among different groups of forest owners has been given scarce attention. Direct measures of forest knowledge in different groups of owners can provide important insights regarding how distant different groups of owners are from the practical matters of the forest. In addition, the simple conceptualizations and measures of knowledge (mainly self-assessments) in previous research may obscure an understanding of what type of competence the owners have. The aim of this study was to examine forest knowledge among individual private forest owners in Sweden and to consider how structural characteristics (e.g., gender, age, size of forest holding) and forest involvement (e.g., certification, involvement in forestry work and forest planning) are related to different forms of knowledge.

\section{Theoretical background}

\section{Conceptualization and measurement of knowledge}

In environmental research, different knowledge types have been distinguished. Declarative knowledge is often differentiated from procedural or action-related knowledge, thus distinguishing between system knowledge (e.g., how environmental systems or a certain aspect of the environmental system, such as climate change, function) versus knowledge of specific actions that can be implemented to achieve a certain goal (Kaiser and Fuhrer 2003; Frick et al. 2004; Díaz-Siefer et al. 2015; Shi et al. 2015; Thorn and Bogner 2018). With regard to the measurement of knowledge, the distinction between objective (or actual) and subjective (or self-rated) assessments of knowledge is important (e.g., Shi et al. 2015). Measures of objective knowledge employ knowledge questions (true/false or multiple choice), whereas subjective knowledge represents a self-assessment of one's knowledge level. The terms familiarity and awareness are often used to describe subjective assessments of whether or not people have heard about relatively novel issues, for example new or invasive plants, pests and pathogens (e.g., Steele et al. 2006; Marzano et al. 2017). Other measures of subjective knowledge generally involve assessments of the level of knowledge, for example ranging from none to extensive. Rather than reflecting an actual knowledge level, however, these measures reflect perceptions of confidence, with clear parallels to concepts such as self-efficacy and perceived behavioural control in psychological models (cf. the theory of planned behaviour, Ajzen 2002; Geiger et al. 2019). Hence, whereas measures of objective and subjective knowledge are likely interlinked, actual knowledge and confidence are distinct constructs. Accordingly, studies supporting subjective knowledge as a predictor of forest management, for example (e.g., Eggers et al. 2014), may be assumed to support the importance of confidence but not actual knowledge. Despite differences in conceptualizations and measurements (and consequently interpretations of data), subjective knowledge is often simply labelled knowledge (Floress et al. 2019), thus obscuring an understanding of the potentially multiple roles of knowledge in management decisions.

\section{Learning environments and knowledge among private forest owners}

Knowledge can be anticipated as the outcome of learning processes. Learning theories focus to different degrees on external reinforcements (behaviourism), the acquisition and processing of information (cognitive theories), and how meaning is created based on experiences (constructivism) (Shunk 2012). Even though different emphasis is given to the learner versus the environment in the different learning approaches, it is reasonable to assume that forest owners' knowledge should be partly dependent on the owners' learning environment.

As a result of for example traditions and socialization processes, structural factors, such as gender, forest acquisition, and size of forest, are associated with the amount of resources (material and social) available to the owners (Lidestav and Nordfjell 2005). For example, until now there are prevailing differences in inheritance practices, influence over the forest, etc., between female and male owners in Europe (Follo et al. 2016). Whereas the father has been found to be an important source of knowledge for both female and male owners, female owners also relied on their partner and male owners were to a greater extent self-taught and took part in 
forestry courses (Häggqvist et al. 2014). Thus, through an interaction between the social structure in society and the individual owner, structural differences may not only lead to differences in social realities, but also differences in learning environments. In line with this reasoning, male owners have been found to report higher levels of subjective knowledge of forest management (i.e., procedural knowledge) than female owners do (Jarrett et al. 2009; Eggers et al. 2014). In addition, resident owners and owners with larger forest estates have been found to display higher subjective knowledge than their counterparts in areas such as management (Eggers et al. 2014; Steele et al. 2006). Similar results have been found for subjective knowledge of financial assistance programmes, for example, with owners of larger holdings and men displaying higher knowledge levels than their counterparts (Sun et al. 2009). A higher educational level has furthermore been found to be associated with higher subjective, but also objective, knowledge of specific topics (e.g., invasive plants, insects) (Steele et al. 2006; Thorn et al. 2019).

By taking forestry courses, communicating with advisors, and interacting with other owners in social networks for example, forest owners are given direct opportunities for learning (Crona and Bodin 2006; André et al. 2017). In line with the reasoning that involvement in forest activities will contribute to learning, owners with a management plan and members of a forest owner association have been found to display higher subjective knowledge (Sun et al. 2009; Creamer et al. 2012). Further, Ingemarson et al. (2006) revealed that different owner categories (based on ownership objectives) displayed varying levels of subjective forest knowledge, with passive owners displaying lower subjective knowledge of the forest than multi-objective owners, conservationists, and economists. Overall, previous studies have considered how knowledge is to some extent contingent on structural characteristics and forest involvement. However, a comprehensive understanding of particularly objective knowledge among forest owners is lacking. In addition, studies have rarely explored procedural knowledge of the range of different management strategies important to fulfil the different goals generally included in the forest policy (e.g., biodiversity and climate adaptation).

\section{The present study}

The development of appropriate forest policy and outreach to private forest owners requires an understanding of not only the structural characteristics of forest owners but also value priorities, management objectives, and attitudes (e.g., Põllumäe et al. 2014; Coté et al. 2016). Despite the importance of knowledge for forest management, however (Floress et al. 2019), scarce attention has been given to the conceptualization and measurement of knowledge in the forest domain. Empirical support for the conceptual distinction between objective and subjective knowledge among forest owners is needed for a more accurate understanding of forest owners' competences and has implications on how to maintain and advance proficiency in private forestry.

This study examined forest knowledge among different groups of individual private forest owners in Sweden. The level of subjective and objective knowledge of forests in general (i.e., declarative knowledge) and of management for different objectives, including production, biodiversity, recreation, climate mitigation, and climate adaptation (i.e., procedural knowledge) were examined in different groups of owners based on the following structural characteristics: gender, age, formal education, residency, forest acquisition, size of forest holding, and length of forest ownership. In addition, relations between objective and subjective forms of knowledge were examined. Finally, to explore the different conditions important for forest owners' knowledge, the role of structural variables and forest involvement variables (i.e., certification, forest owner association membership, involvement in forestry work and involvement in forest planning) for objective and subjective knowledge were examined. By examining multiple predictors simultaneously, the importance of each variable while controlling for other relevant variables was assessed. Analyses were based on the assumption that structural variables should be important for the owners' learning opportunities and consequently associated with knowledge levels (Lidestav and Nordfjell 2005; Follo et al. 2016). There is partial empirical support for this since being a male owner, owning a larger forest, and being a resident owner have been found to be associated with higher subjective knowledge levels (e.g., Eggers et al. 2014). Given that different indicators of forest involvement can be considered to more directly reflect the individual owner's learning environment, involvement variables were expected to be more closely associated with knowledge than structural factors. However, whereas the owner may outsource tasks associated with certification and the management plan, and it is possible to be a passive members of a forest owner association (e.g., Eggers et al. 2014; Kronholm 2016), involvement in practical forestry work and forest planning are likely to be more precise indicators of the individual owner's involvement.

\section{Materials and methods}

\section{Study context}

Almost 70\% of Sweden's land area is covered by forests, dominated by coniferous trees (primarily Norway spruce and Scots pine) (Swedish University of Agricultural Science [SLU] 2018). The economic significance of forests in Sweden is reflected in, for example, the large production of 
roundwood and sawnwood (Eurostat 2017). However, there are several demands on the forest. Swedish forest policy stipulates that the environmental (e.g., biodiversity) and production objectives are equally important and highlight using the forest for climate mitigation as well as the need to adapt the forest to climate change (Swedish Gov. Bill 2007/08:108). The Swedish forest is predominantly private, with approximately half of it owned by close to 330,000 individual private forest owners (Swedish Forest Agency [SFA] 2014). According to the Swedish Forestry Act, forest owners possess a large degree of freedom in managing their forest (e.g., Nichiforel et al. 2018), although some obligatory measures are in place, such as regeneration after clear-felling and removing dead trees exceeding $5 \mathrm{~m}^{3}$ before a certain date to avoid the risk of insect damage. Although only about $27 \%$ of the forest in Europe is privately owned, the share varies significantly within and across countries (Pulla et al. 2013). In addition, the institutional frameworks are diverse and the emphasis placed on for example production or recreation in the national forest policy vary, even in countries with a significant amount of individual private owners, such as Finland, Germany, Estonia, and Portugal. However, societal trends including for example urbanization, ageing, and an increased share of female owners are considered relevant across Europe (Hirsch et al. 2007).

\section{Respondents}

In 2018, a survey company (Attityd i Karlstad AB) conducted a postal survey of individual private forest owners in Sweden. The owners were randomly selected from the property register, with the criteria that they be $20-80$ years old and own more than 5 ha of forest land $(n=3000$; after removal of over-coverage, $n=2894)$. After two reminders, the response rate was $43 \%(n=1251)$. Although the selection procedure was associated with some irregularities (i.e., the random sample selection was made in two steps, and a supplementary selection of 167 owners had to be made to compensate for inaccurately including owners not in the target population), the sample was largely comparable to those in previous studies of forest owners in Sweden (cf. Eriksson 2017). In addition, calibrated weights (controlling for deviations in gender, age, and size of forest holdings) were used in the analyses to increase the representativeness of the sample.

\section{Questionnaire}

The questionnaire was 12 pages long, but only the questions relevant to this study are described below. Structural variables, i.e., sociodemographics and ownership characteristics, included gender (male/female), age (numeric), formal education (five categories), residency (resident and four categories representing distance from closest forest holding), forest acquisition (bought on the open market, bought from relatives, inheritance and gift, with the possibility to tick more than one box), size of forest holding (numeric), and length of forest ownership (numeric). Involvement variables comprised whether or not they were members of a forest owner association (including the possibility to answer 'don't know'), whether or not they had a certified forest business, and whether or not they had an updated forest management plan. In addition, the owners were asked to what extent they were involved in forest planning (1 item) and practical forestry work (i.e., planting, clearing, thinning, and final cut) (4 items) on five-point scale (after reverse coding the scale: $1=$ Nothing, leave everything to others, $2=\mathrm{A}$ little, $3=$ About half, $4=$ A great deal, $5=$ Everything). The sum of the four items was used to create a measure of practical forestry work. Higher values indicate that the owners do more themselves.

\section{Objective knowledge}

The objective knowledge scales, one reflecting general knowledge and five reflecting one type each of procedural knowledge, were constructed based on previous research on knowledge scales (considering, e.g., difficulty levels) (Frick et al. 2004; Díaz-Siefer et al. 2015) and expert knowledge of forest management. Some of the questions were inspired by the battery of questions at Skogskunskap.se (a Web portal with facts about forests). Facts about forest and forest management in Sweden were used to construct individual questions for the knowledge scales, and the questions were subsequently pretested by a group of private forest owners. In the pretests, the owners answered the questions, evaluated and commented on their clarity, etc., and rated them on a three-point scale: easy, medium, or difficult. After revisions based on the pretests, a final set of questions was included in the questionnaire, reflecting general knowledge (six questions, two for each of the three difficulty levels) and five procedural knowledge scales (each assessed by means of four questions: one easy, two medium, and one difficult). The questions were multi-response, with three to six possible response options to each question. Answers were coded in three categories $-0=$ wrong, $.5=$ partly correct, and $1=$ correct-resulting in a scale of $0-6$ on general knowledge and a scale of $0-4$ on procedural knowledge.

\section{Subjective knowledge}

To assess subjective knowledge, single items reflecting general knowledge and five types of procedural knowledge, respectively, were included. Drawing on previous research on subjective knowledge (e.g., McFarlane and Watson 2008), the following question was used: How much knowledge do you consider that you have about the following? General 
knowledge about forests in Sweden (e.g., tree species, damage, ownership conditions) [general]; Forest management aiming for good forest growth [production management]; Forest management used to preserve biodiversity [biodiversity management]; Forest management contributing to an attractive recreation forest [recreation management]; Forest management aiming to use the forest for climate mitigation [mitigation management]; and Forest management adjusted to a warmer climate [adaptation management]. Answers were provided on a four-point scale $(1=$ No knowledge at all, $2=$ Little knowledge, $3=$ Certain knowledge, $4=$ Extensive knowledge).

\section{Analyses}

The analyses were conducted using SPSS 24 statistics software (IBM Corp. 2016). First, descriptive analyses were performed. The structural characteristics of the sample was analysed based on unweighted data. However, since the sample deviated slightly from the population of forest owners in Sweden, weighted data was used for the remaining analyses. The level of involvement in the sample was analysed and descriptive analyses of knowledge questions were conducted. Second, univariate ANOVAs, including partial eta ${ }^{2}$, were used for the group comparison with structural variables as factor and objective knowledge (general and five types of procedural knowledge) and subjective knowledge (general and five types of procedural knowledge) as dependent variables. A rule of thumb for the interpretation of partial eta ${ }^{2}$ for analyses with only one independent variable is to consider a value of $.01, .06$, and $>.14$ to be small, medium, and large, respectively (Cohen 1988). The structural variables were coded according to the following: gender (male, female), age group (20-49 years, 50-64 years, 65-80 years), education (no university degree, university degree), residency (non-resident, resident), forest acquisition (only inheritance or gift, bought at least part of the land), size of forest holding (1-20 ha, 21-50 ha, 51-100 ha, 101 ha-) and length of ownership (0-15 years, 16-26 years, 27-36 years, 37 years-). For variables with more than two groups, we controlled for multiple comparisons using Bonferroni correction. Third, the relations between objective and subjective knowledge were examined by means of an exploratory factor analysis with oblique rotation on the 12 knowledge measures (six measures for objective and subjective knowledge each). In addition, Cronbach's alpha was used to assess the internal reliability of the factors and Pearson $r$ was used to calculate the bivariate correlation. Fourth, the importance of structural variables and involvement variables as predictors of objective and subjective knowledge was examined by means of hierarchical regression analyses using the factor scores as dependent variables. In the first step the structural variables (i.e., gender (dummy), age (continuous), education (dummy), residency (dummy), forest acquisition (dummy), length of ownership (continuous) and size of forest holding (continuous), ) were included, and in the second step the involvement variables (i.e., certification (dummy: Yes $=1$ ), updated management plan (dummy: Yes $=1$ ), membership in forest owner association (dummy: Yes $=1$, the 2\% don't know answers were treated as no), involvement in forest planning (scale 1-5), and involvement in practical forestry work (scale 1-20)) were added.

\section{Results}

\section{Descriptive analyses}

The sample characteristics are displayed in Table 1 . Although the sample contained slightly fewer female owners, young owners, and owners with a small forest holding compared to the selection frame, calibrated weights were used in the analyses to make the sample comparable to the population of forest owners, thus controlling for these deviations. In the sample of owners, $26 \%$ owned a certified forest, $41 \%$ had an updated management plan, and $47 \%$ stated that they were members of a forest owner association. Results furthermore indicate that the involvement in forest planning and practical forestry work was just above average $(M=3.57, \mathrm{SD}=1.58$, on a scale from 1 to 5 , and $M=10.30$, $\mathrm{SD}=5.30$ on a scale from 1 to 20 , respectively).

For the objective knowledge questions, the average percentage of correct answers was highest for general forest knowledge (i.e., declarative knowledge) at $60 \%$, although knowledge of climate adaptation management was only slightly lower, with an average of 53\% correct answers. The remaining knowledge scales had an average percentage of correct answers varying from $32 \%$ for climate mitigation to $39 \%$ for production management. Because the objective knowledge scales have not been tested and evaluated previously, results on the different objective knowledge scales should not be compared directly. The self-rated knowledge for production management was highest, with $4.8 \%$ stating no knowledge, $27 \%$ little knowledge, 53\% certain knowledge, and $16 \%$ extensive knowledge. In addition, the owners reported relatively high general forest knowledge (4.6\% no knowledge, $31 \%$ little knowledge, 54\% certain knowledge, and $10 \%$ extensive knowledge). Subjective knowledge of biodiversity and recreation management was slightly lower (biodiversity $7 \%, 40 \%, 45 \%$, and $8 \%$; recreation $10 \%, 39 \%$, $44 \%$, and $7 \%$ ), and even fewer reported high levels of knowledge of mitigation and adaptation (mitigation $12 \%, 50 \%$, $34 \%, 4.7 \%$; adaptation $22 \%, 52 \%, 24 \%, 2.2 \%$ ). Thus, results indicate that the owners display higher subjective knowledge of production management and general forest matters, but lower subjective knowledge of mitigation and adaptation. 
Table 1 Sample characteristics

\begin{tabular}{ll}
\hline Gender (female) & $19 \%(n=240)$ \\
Mean age & 62 years $(\mathrm{SD}=11)$ \\
Education & $31 \%(n=380)$ university degree \\
Occupation & $29 \%(n=360)$ part-time or full-time work \\
& $23 \%(n=283)$ business \\
& $40 \%(n=494)$ retired \\
& $8 \%(n=114)$ other \\
& $52 \%(n=641)$ resident owner \\
& $15 \%(n=192)<10$ km from the closest \\
Residency & forest estate \\
& $32 \%(n=399) 10$ km or further away from \\
& the closest forest estate \\
& 92 ha/20 ha $(\mathrm{SD}=261)$ \\
Size of forest holding & \\
(mean/median ha pro- & \\
ductive forest land) & \\
Length of forest owner- & 27 years $(\mathrm{SD}=13)$ \\
ship (mean years) & \\
Forest acquisition & $33 \%(n=398)$ inherited forest or gift \\
& $67 \%(n=822)$ having bought at least part \\
& of the forest \\
Region for the forest & $18 \%(n=219)$ North Sweden \\
holding & $44 \%(n=554)$ Middle Sweden \\
& $38 \%(n=476)$ South Sweden
\end{tabular}

$N=1251$. Unweighted data

${ }^{a}$ Forest regions correspond to the organizational setup of the Swedish Forest Agency

\section{Group comparisons}

Means, standard deviations, and partial eta ${ }^{2}$ for the group comparisons are displayed in Online Resource 1 (see Table 1.1 for objective knowledge and Table 1.2 for subjective knowledge.). The overall pattern of results is described below. With regard to objective knowledge, differences between the sociodemographic groups were minor with partial eta ${ }^{2}$ values no higher than .036 . Nevertheless, compared to female owners, male owners were found to have significantly higher objective knowledge of production management in particular, but differences were significant also for general knowledge, as well as for knowledge of mitigation and adaptation management. Results further revealed that younger owners displayed higher general forest knowledge and higher knowledge of production, biodiversity, and adaptation management, than older owners did. Owners with a university degree displayed higher objective knowledge, except in relation to knowledge of production management. With regard to the relation between forest characteristics and objective knowledge, the partial eta ${ }^{2}$ values were no higher than .015 for residency, forest acquisition, and length of forest ownership, but was generally higher for size of forest ownership. Compared to owners of smaller forest holdings, owners with larger holdings displayed higher objective knowledge of general forest matters as well as production, biodiversity, and adaptation management, with the greatest difference evident for production management (partial eta $^{2}=.068$ ).

Results further revealed that gender differences were greater in subjective compared to objective knowledge, with partial eta ${ }^{2}$ values ranging from .012 to .079 for the different measures. Males reported higher subjective knowledge levels, particularly regarding production management and general forest issues. However, age and education were less important for subjective knowledge. There were no differences in subjective knowledge between the age groups and differences between owners with and without a university degree were limited (partial eta ${ }^{2}=.000-.008$ ). Comparable to objective knowledge, size of forest holding was relevant for subjective knowledge with partial eta ${ }^{2}$ values ranging from .031 to .073. Owners with larger forest holdings reported higher subjective knowledge throughout, with the greatest difference for production management. In addition, forest acquisition was relevant for subjective knowledge with owners who had bought their land rating their knowledge level higher in relation to all knowledge measures (partial eta ${ }^{2}=.021-.043$ ). Even though the long-time owners reported higher levels of subjective knowledge in relation to all measures except recreation management, length of forest ownership explained only a small amount of variance in subjective knowledge (partial eta ${ }^{2}=.007-.020$ ). Comparable to objective knowledge, residency explained only minor differences in subjective knowledge with none of the partial eta ${ }^{2}$ values exceeding .006 .

Overall, size of forest holding was important for all measures of subjective knowledge as well as for, in particular, objective knowledge of production management. A similar pattern was evident for gender. Illustrations of how size of forest holding and gender were associated with procedural knowledge measures are displayed in Figs. 1 and 2 , respectively. Notably, a divergent pattern of results was found for education and objective knowledge, with education being significantly associated with several of the objective knowledge measures, but not knowledge of production management.

\section{Relations between objective and subjective knowledge}

The exploratory factor analysis of the 12 knowledge measures revealed two components (eigenvalues 4.720, 1.920) explaining 55\% of the variance. Whereas the first component contained subjective knowledge measures, the second included measures of objective knowledge. Internal reliability analyses revealed that the component measures displayed high reliability $(\alpha=.90$ for subjective knowledge 


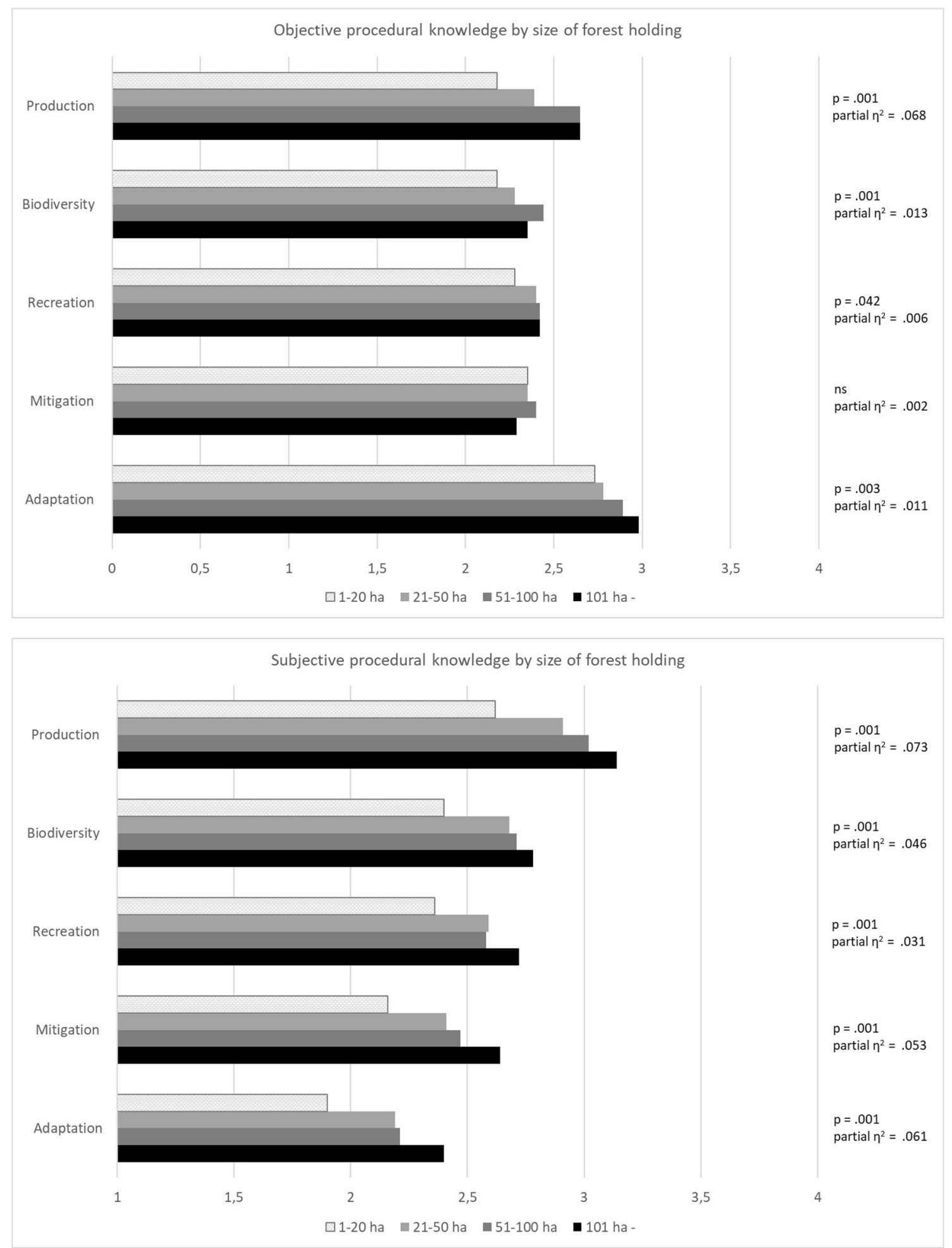

Fig. 1 Means for objective knowledge (top panel) and subjective knowledge (bottom panel) relating to management for production, biodiversity, recreation, mitigation, and adaptation, by size of for-

and $\alpha=.72$ for objective knowledge). The distribution for the resulting factor scores for objective and subjective est holding (scale $0-4$ and $1-4$, respectively, including $p$ values (ns = non-significant $)$ and partial eta $\left.{ }^{2}\right)$

knowledge, respectively, are available in Online Resource 2. Although a significant positive correlation was found 

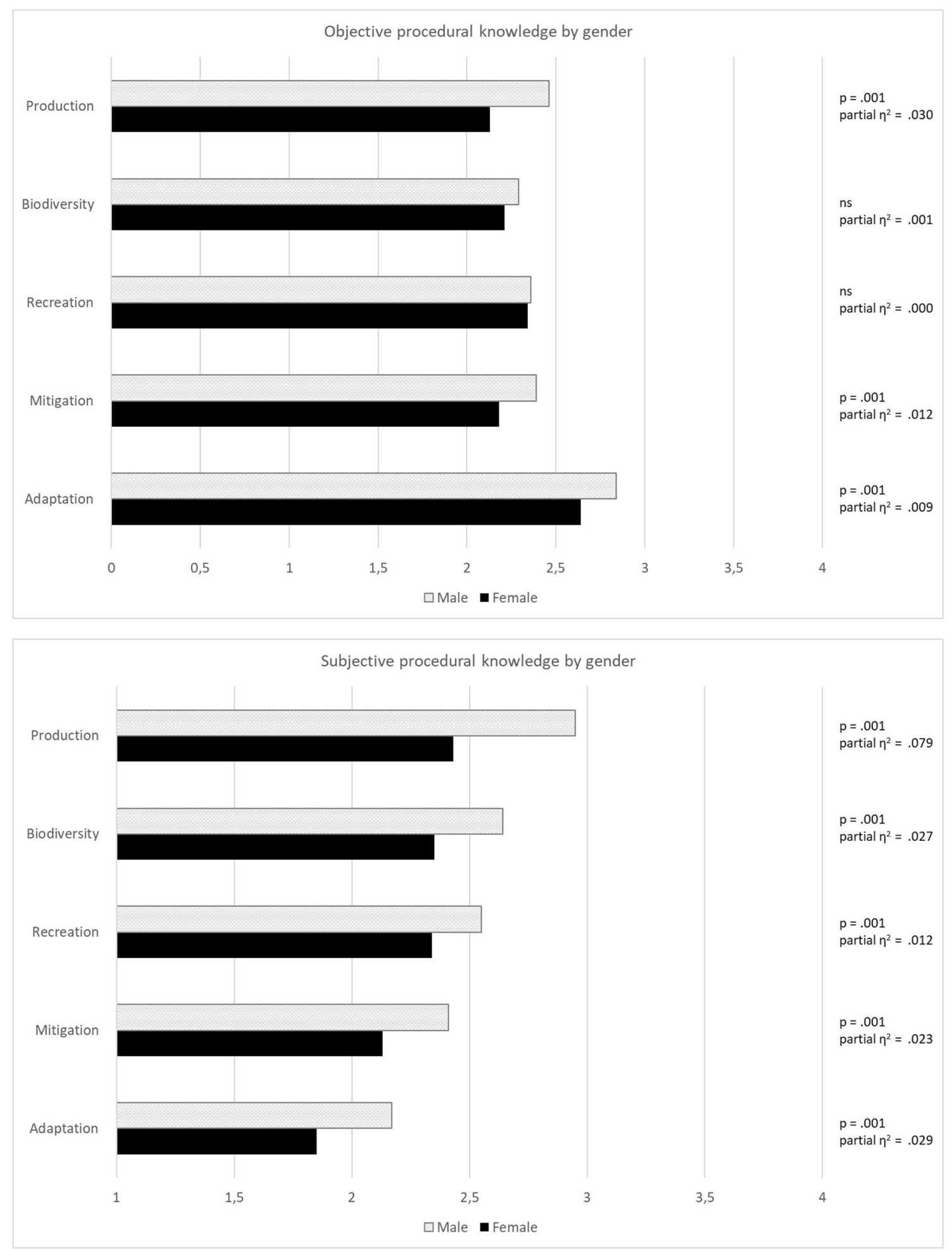

Fig. 2 Means for objective knowledge (top panel) and subjective knowledge (bottom panel) relating to management for production, biodiversity, recreation, mitigation, and adaptation, by gender (scale $0-4$ and 1-4, respectively, including $p$ values (ns =non-significant) and partial eta ${ }^{2}$ )

between the two forms of knowledge $(r=.32 * * *)$, results supported a distinction between objective and subjective knowledge.

\section{Predictors of objective and subjective knowledge}

Results from the hierarchical regression analyses of 
structural and involvement variables as determinants of objective and subjective knowledge are displayed in Table 2. There was no evidence of collinearity (in step 2, VIF ranged from 1.055 to 1.888). For objective knowledge, gender, age, education, and length of ownership were significant predictors in the first step. Being male, younger, having a university degree, and owning the forest for a longer time were associated with higher objective knowledge levels. However, only age, education, and length of forest ownership remained significant in the second step of the analysis, indicating that differences in knowledge as a result of gender can be explained by the involvement variables. More specifically, certification, membership in a forest owner association, and involvement in forest planning were significant predictors.

For subjective knowledge, gender, education, forest acquisition, length of ownership, and size of forest holding were significant predictors in the first step of the analysis,

Table 2 Hierarchical regression analyses of objective and subjective knowledge, respectively, in two steps: (1) structural variables and (2) structural and forest involvement variables

\begin{tabular}{|c|c|c|}
\hline & $\begin{array}{l}\text { Objective } \\
\text { knowledge } \\
\beta\end{array}$ & $\begin{array}{l}\text { Subjective } \\
\text { knowledge } \\
\beta\end{array}$ \\
\hline \multicolumn{3}{|l|}{ Step 1} \\
\hline Gender $(1=$ female $)$ & $-.10 * *$ & $-.19 * * *$ \\
\hline Age & $-.15^{* * *}$ & .01 \\
\hline Education ( $1=$ university degree $)$ & $.24 * * *$ & $.06^{*}$ \\
\hline Residency ( 1 = resident owner) & .04 & -.01 \\
\hline Acquisition ( 1 = bought $)$ & .05 & $.15^{* * * *}$ \\
\hline Length of forest ownership & $.13 * *$ & $.14 * * *$ \\
\hline Size of forest & .03 & $.10 * * *$ \\
\hline$R^{2}$ & $.08^{* * *}$ & $.11 * * *$ \\
\hline $\operatorname{Adj} R^{2}$ & $.08 * * *$ & $.10^{* * * *}$ \\
\hline \multicolumn{3}{|l|}{ Step 2} \\
\hline Gender $(1=$ female $)$ & -.03 & $-.08 * *$ \\
\hline Age & $-.11 * *$ & .06 \\
\hline Education ( $1=$ university degree $)$ & $.22 * * *$ & .04 \\
\hline Residency ( $1=$ resident owner $)$ & .02 & -.03 \\
\hline Acquisition ( 1 = bought $)$ & .03 & $.11 * * *$ \\
\hline Length of forest ownership & $.08^{*}$ & $.10^{*}$ \\
\hline Size of forest & .02 & $.07 *$ \\
\hline Certified & $.10 * *$ & $.12 * * *$ \\
\hline Updated management plan & .02 & $.13 * * *$ \\
\hline Member in forest owner organization & $.08 *$ & .02 \\
\hline Involved in forest planning & $.23 * * *$ & $.27 * * *$ \\
\hline Involved in practical forestry work & .00 & .03 \\
\hline$R^{2}$ & $.16^{* * *}$ & $.22 * * *$ \\
\hline $\operatorname{Adj} R^{2}$ & $.14 * * *$ & $.21 * * *$ \\
\hline$\Delta R^{2}$ & $.07 * * *$ & $.11 * * *$ \\
\hline
\end{tabular}

Weighted data. Effective sample size $=973$

$* * * p<.001 ; * * p<.01 ; * p<.05$ and except for education, the same variables remained significant in the second step. Being male, having bought at least some of the land, owning the forest for a longer time, and owning more forest land were associated with higher subjective knowledge levels. Among the involvement variables, certification, having an updated management plan, and involvement in forest planning were significant predictors of subjective knowledge. Overall, the structural variables explained $8 \%$ of the variance in objective knowledge and $10 \%$ in subjective knowledge. The inclusion of involvement variables increased the variance to $14 \%$ for objective knowledge, and the full regression model explained $21 \%$ of the variance in subjective knowledge.

\section{Discussion}

Changes among private forest owners have triggered an interest in how policy instruments and support services should be adapted to fit contemporary forest owners (Hogl et al. 2005; Pynnönen et al. 2018; Upton et al. 2019). Even though there is an increasing interest for issues relating to learning in the forest domain (André et al. 2017), scarce attention has been given to the level of forest knowledge among different groups of forest owners. With a thorough conceptualization and direct measures of different types of forest knowledge, this study addresses this knowledge gap.

The importance of structural characteristics for objective and subjective knowledge was confirmed in this study. The greatest group differences were found between male versus female owners, and between owners with larger versus smaller forest holdings for subjective knowledge of production management. Results supported gender differences, in line with previous research, with male owners reporting higher subjective knowledge than female owners (cf. Eggers et al. 2014). In addition, the study revealed higher levels of objective knowledge (except that of biodiversity and recreation management) among male compared to female owners. Notably, though differences were substantially more pronounced for subjective than for objective knowledge, and there was no difference in objective knowledge after having considered the level of involvement in forestry. Thus confirming the importance of involvement to understand differences between female and male owners (Eriksson 2018). Whereas the consideration of additional involvement variables may further reduce the gender difference in subjective knowledge, even with similar levels of involvement, the gendered forestry sector dominated by men and traditional perceptions of masculinity may contribute to female owners questioning their own competence (Häggqvist et al. 2014; Andersson and Lidestav 2016). Consistent with previous research (Eggers et al. 2014), owners with larger forest holdings reported higher subjective knowledge than did 
owners with smaller holdings. Furthermore, except regarding recreation and mitigation, similar results were found for objective knowledge. Although the size of the forest holding was only a significant predictor of the overall measure of subjective knowledge in the regression models, owners with larger forest holdings displayed substantially higher objective knowledge of production management than did owners with smaller holdings. Thus, results support the link between production management and large forest estates that has been highlighted in previous research (cf. Eggers et al. 2014; Ingemarson et al. 2006; Coté et al. 2016). However, in contrast to previous studies (cf. Eggers et al. 2014), this study revealed that residency was less relevant for knowledge levels among forest owners. Thus, concerns associated with non-resident owners being absent from the local community and mentally distant (Nordlund and Westin 2011; Huff et al. 2017) were not mirrored in lower levels of forest knowledge among non-resident owners in this study.

Age and formal education displayed more pronounced differences in objective than in subjective knowledge. Notably though, younger owners displayed higher objective knowledge than older owners did (except in relation to recreation and mitigation management). One potential reason for this result is that the oldest age group, being 65 years or older, may be less accustomed to answering questions in this format than younger owners, and other ways of assessing knowledge (e.g., face-to-face) might have resulted in different results. The importance of a higher education for more objective knowledge was generally confirmed. However, a higher education was not associated with more objective knowledge of production management. Since production management has played a significant role in Swedish forestry (Bush 2010), things like experience of forest management and personal networks are likely to be more important than formal education for the acquisition of this type of knowledge. Similarly, the weaker relationship between education and subjective knowledge is reasonable since self-activity in the forest context is even more likely than higher education to boost subjective knowledge of forest matters (Häggqvist et al. 2014). Notably, though, if forestry education had been examined, results would likely have been different.

As expected, forest involvement variables were able to explain knowledge, over and above structural variables. Whereas previous studies have revealed links between different types of forest involvement and subjective knowledge (Sun et al. 2009; Creamer et al. 2012), this study showed that certification and membership in forest owner associations were also associated with higher objective forest knowledge. Most important for both objective and subjective knowledge was involvement in forest planning, although involvement in practical forestry work was not related to any of the knowledge measures. Notably, though because this was a crosssectional study, its results can confirm the importance of the interplay between active and strategic decisions (reflected in the examined involvement variables) and knowledge levels, but not the direction of causality. It is entirely possible, and may even be considered likely, that there are two-way feedback loops where involvement increases actual knowledge and confidence, and actual knowledge and confidence encourages involvement. Based on the results, however, it is possible to determine that different types of involvement are independently related to knowledge, thus indicating that, while there is no one to one relationship, more forms of involvement among forest owners are associated with higher knowledge levels. Encouraging contacts with different forest organizations thereby increasing the opportunities for exchange may be one way to facilitate proficiency among forest owners, but results also suggest that support of individual decision-making and planning (e.g., using web based tools) may be valuable. Although practical forestry work was not important for the dimensions of knowledge examined in this study, having experience of planting, clearing, or thinning, for example, may be important for using theoretical forest knowledge in actual forest management practices.

In line with suggestions that low levels of forest knowledge may be linked to a weak sense of control among forest owners (Lähdesmäki and Matilainen 2014), this study empirically confirmed that objective knowledge and subjective knowledge are significantly correlated. However, a distinction between actual knowledge, assessed using objective knowledge scales, and confidence, assessed using subjective knowledge scales, was revealed, as suggested in the Introduction. This distinction is not only important for an appropriate understanding of forest owners, but has implications for governance as well. Although different forms of forest involvement are likely to increase different types of knowledge, policy and outreach can also be specifically designed to increase actual knowledge or confidence, depending on the needs in a particular situation. By drawing on the parallels between subjective knowledge and the concept of selfefficacy (e.g., Ajzen 2002), a fruitful strategy to increase the level of subjective knowledge may be to provide for example action planning and feedback to boost the owners' belief in their ability to engage in a particular type of management. Whereas it is not appropriate to compare the measures of objective knowledge, the present study suggests that the owners have more confidence when it comes to production management and general forest matters, but lower confidence when it comes to mitigation and adaptation management. Thus, to facilitate forest management for the new strivings related to climate change in forest policy (Swedish Gov. Bill 2007/08:108), there is a need to build confidence among owners in these ways of managing the forest.

When interpreting results, some limitations of this study should be considered. Whereas structural conditions and forest involvement were relevant for understanding potential 
learning environments for forest owners, this study used indicators of learning environments and was partly exploratory. Guided by learning theories, future studies may examine learning processes and outcomes (i.e., objective and subjective knowledge) in different learning environments to provide detailed insights for increasing the proficiency of the forest sector. Furthermore, given the importance of forest involvement for learning in this study, other learning environments should also be examined (e.g., formal and informal networks, contacts with forest agencies) (cf. Stoettner and Ní Dhubháin 2019) and additional types of knowledge, such as scientific forest knowledge and local forest knowledge, should be considered. Even though a representative sample of forest owners were surveyed, and calibrated weights were used to avoid biases based on gender, age and size of forest holding, it is likely that owners more interested in the topic of this study participated to a greater extent than other owners did. While the measures of objective knowledge were carefully developed based on previous research on the measurement of knowledge, forest expertise, and pretests among forest owners, repeated tests in different samples are needed to enable a comparison of different types of knowledge. Whereas the objective knowledge scales and the composite measure of subjective knowledge displayed good internal reliability, single items were used to assess the different types of subjective knowledge, preventing calculations of internal reliability. Measures of effect size provide information beyond significance levels, but they are context dependent and several considerations need to underlie interpretations. For example, whereas the univariate analyses of structural variables revealed that mainly size of forest and gender were strongly associated with one or several of the knowledge measures (reaching medium effect sizes), the multivariate analyses suggest that for example education has a substantial impact on the composite measure of objective knowledge.

\section{Conclusions}

This study suggests that structural characteristics and individual involvement with forest issues are relevant to understand forest owners' learning environments. In addition, results confirm the need to differentiate between objective knowledge, as a measure of actual knowledge, and subjective knowledge assessing confidence. Being a male owner, owning a larger forest holding, having bought the land, and having owned the forest for a long time were associated with higher confidence in managing the forest. Although several of these variables were associated with higher levels of objective knowledge, the correlation diminished when controlling for forest involvement. In contrast, younger owners and owners with a university degree displayed higher actual knowledge than their counterparts, but there was no support for differences in confidence. Results from this study may be used to improve the understanding of private forest owners, thus having implications on forest governance and outreach to forest owners. First, considering the distinction between actual knowledge and confidence makes is possible to adjust policy accordingly (e.g., to avoid targeting actual forest knowledge when owners actually need to build confidence). Second, in outreach aiming to increase forest knowledge among owners, it is important to be aware that involvement variables provide a more precise identification of appropriate target groups, rather than merely relying on structural characteristics.

Acknowledgements The authors would like to thank the participating forest owners for completing the survey and reviewers for their comments.

Funding Open access funding provided by Umea University. This study was funded by Brattåsstiftelsen (Grant No. F17:03).

Data availability The dataset analysed during the current study is available from the corresponding author upon reasonable request after the completion of the project.

\section{Compliance with ethical standards}

Conflict of interest The authors declare that they have no conflict of interest.

Informed consent Participation in the survey was voluntary and based on informed consent.

Ethics The survey contained no personally sensitive information (e.g., about health or political opinions). Only the survey company had access to the personal information during the data collection, and the code key was deleted once the collection phase was completed.

Open Access This article is licensed under a Creative Commons Attribution 4.0 International License, which permits use, sharing, adaptation, distribution and reproduction in any medium or format, as long as you give appropriate credit to the original author(s) and the source, provide a link to the Creative Commons licence, and indicate if changes were made. The images or other third party material in this article are included in the article's Creative Commons licence, unless indicated otherwise in a credit line to the material. If material is not included in the article's Creative Commons licence and your intended use is not permitted by statutory regulation or exceeds the permitted use, you will need to obtain permission directly from the copyright holder. To view a copy of this licence, visit http://creativecommons.org/licenses/by/4.0/.

\section{References}

Ajzen I (2002) Perceived behavioral control, self-efficacy, locus of control, and the theory of planned behavior. J Appl Soc Psychol 32:665-683 
Andersson E, Lidestav G (2016) Creating alternative spaces and articulating needs: challenging gendered notions of forestry and forest ownership through women's networks. For Policy Econ 67:38-44

André K, Baird J, Gerger Swartling A, Vulturius G, Plummer R (2017) Analysis of Swedish forest owners' information and knowledge-sharing networks for decision-making: insights for climate change communication and adaptation. Environ Manag 59:885-897

Bellassen V, Luyssaert S (2014) Carbon sequestration: managing forests in uncertain times. Nature 506:153-155

Blanco V, Brown C, Rounsevell M (2015) Characterising forest owners through their objectives, attributes and management strategies. Eur J Forest Res 134:1027-1041

Blanco V, Brown C, Holzhauer S, Vulturius G, Rounsevell MD (2017) The importance of socio-ecological system dynamics in understanding adaptation to global change in the forestry sector. J Environ Manag 196:36-47

Bush T (2010) Biodiversity and sectoral responsibility in the development of Swedish Forestry Policy, 1988-1993. Scand J Hist 35:471-498

Cohen J (1988) Statistical power analysis for the behavioral sciences, 2nd edn. Lawrence Erlbaum, Hillsdale

Cook SL, Ma Z (2014) The interconnectedness between landowner knowledge, value, belief, attitude, and willingness to act: Policy implications for carbon sequestration on private rangelands. J Environ Manag 134:90-99

Coté M-A, Gilbert D, Nadeau S (2016) Impact of changes in the sociological characteristics of small-scale forest owners on timber harvesting behavior in Quebec, Canada. Small-Scale For 15:375-392

Creamer SF, Blatner KA, Butler BJ (2012) Certification of family forests: what influences owners' awareness and participation? J Forest Econ 18:131-144

Crona B, Bodin Ö (2006) What you know is who you know? Communication patterns among resource users as a prerequisite for co-management. Ecol Soc 11:7

Díaz-Siefer P, Neaman A, Salgado E, Celis-Diez JL, Otto S (2015) Human-environment system knowledge: a correlate of pro-environmental behavior. Sustainability-Basel 7:15510-15526

Eggers J, Lämås T, Lind T, Öhman K (2014) Factors influencing the choice of management strategy among small-scale private forest owners in Sweden. Forests 5:1695-1716

Eriksson L (2012) Exploring underpinnings of forest conflicts: a study of forest values and beliefs in the general public and among private forest owners in Sweden. Soc Nat Resour 25:1102-1117

Eriksson L (2017) The importance of threat, strategy, and resource appraisals for long-term proactive risk management among forest owners in Sweden. J Risk Res 20:868-886

Eriksson L (2018) Explaining gender differences in private forest risk management. Scand J Forest Res 33:716-723

Eurostat (2017) Agriculture, forestry, and fishery statistics. Statistical books. Eurostat, Luxembourg

Felton A, Nilsson U, Sonesson J, Felton AM, Roberge JM, Ranius T et al (2016) Replacing monocultures with mixed-species stands: ecosystem service implications of two production forest alternatives in Sweden. Ambio 45(Suppl 2):124-139

Ficko A, Lidestav G, Ní Dhubháin A, Karppinen H, Zivojinovic I, Westin K (2017) European private forest owner typologies: a review of methods and use. For Policy Econ 99:21-31

Floress K, Huff ES, Snyder SA, Koshollek A, Butler S, Allred SB (2019) Factors associated with family forest owner actions: a votecount metaanalysis. Landsc Urban Plan 188:19-29

Follo G, Lidestav G, Ludvig A, Vilkriste L, Hujala T, Karppinen H et al (2016) Gender in European forest ownership and management: reflections on women as "new forest owners". Scand J For Res 32:174-184
Frick J, Kaiser FG, Wilson M (2004) Environmental knowledge and conservation behavior: exploring prevalence and structure in a representative sample. Pers Indiv Differ 37:1597-1613

Geiger SM, Geiger M, Wilhelm O (2019) Environment-specific vs. general knowledge and their role in pro-environmental behavior. Front Psychol 10:718

Häggqvist P, Berg Lejon S, Lidestav G (2014) Look at what they do-a revised approach to communication strategy towards private forest owners. Scand J For Res 29:697-706

Haugen K, Karlsson S, Westin K (2016) New forest owners: change and continuity in the characteristics of Swedish non-industrial private forest owners (NIPF owners) 1990-2010. Small-Scale For 15:533-550

Hirsch F, Korotkov A, Wilnhammer M (2007) Private ownership in Europe. Unasylva 228(58):23-25

Hogl K, Pregernig M, Weiss G (2005) What is new about new forest owners? A typology of private forest ownership in Austria. SmallScale For Econ Manag Policy 4:325-342

Huff ES, Leahy JE, Kittredge DB, Noblet CL, Weiskittel AR (2017) Psychological distance of timber harvesting for private woodland owners. For Policy Econ 81:48-56

IBM Corp (2016) IBM SPSS Statistics for Windows, Version 24.0. IBM Corp

Ingemarson F, Lindhagen A, Eriksson L (2006) A typology of smallscale private forest owners in Sweden. Scand J Forest Res 21:249-259

Jarrett A, Gan J, Johnson C, Munn IA (2009) Landowner awareness and adoption of wildfire programs in the southern United States. J Forest 107:113-118

Kaiser FG, Fuhrer U (2003) Ecological behavior's dependency on different forms of knowledge. Appl Psychol-Int Rev 52:598-613

Klapwijk MJ, Bylund H, Schroeder M, Björkman C (2016) Forest management and natural biocontrol of insect pests. Forestry $89: 253-262$

Kronholm T (2016) How are Swedish forest owners' associations adapting to the needs of current and future members and their organizations? Small Scale For 15:413-432

Lähdesmäki M, Matilainen A (2014) Born to be a forest owner? An empirical study of the aspects of psychological ownership in the context of inherited forests in Finland. Scand J For Res 29:101-110

Lidestav G, Nordfjell T (2005) A conceptual model for understanding social practices in family forestry. Small-Scale For Econ Manag Policy 4:391-408

Lindner M, Fitzgerald JB, Zimmermann NE, Reyer C, Delzon S, van der Maaten E et al (2014) Climate change and European forests: what do we know, what are the uncertainties, and what are the implications for forest management? J Environ Manag 146:69-83

Marzano M, Fuller L, Quine CP (2017) Barriers to management of tree diseases: framing perspectives of pinewood managers around Dothistroma Needle Blight. J Environ Manag 188:238-245

McFarlane BL, Watson DOT (2008) Perceptions of ecological risk associated with Mountain Pine Beetle (Dendroctonus ponderosae) infestations in Banff and Kootenay National Parks of Canada. Risk Anal 28:121-203

Nichiforel L, Keary K, Deuffic P, Weiss G, Thorsen BJ, Winkel G, Bouriaud L (2018) How private are Europe's private forests? A comparative property rights analysis. Land Use Policy 76:535-552

Nordlund A, Westin K (2011) Forest values and forest management attitudes among private forest owners in Sweden. Forests 2:30-50

Peura M, Burgas D, Eyvindson K, Repo A, Mönkkönen M (2018) Continuous cover forestry is a cost-efficient tool to increase multifunctionality of boreal production forests in Fennoscandia. Biol Conserv 217:104-112

Põllumäe P, Korjus H, Paluots T (2014) Management motives of Estonian private forest owners. For Policy Econ 42:8-14 
Pulla P, Schuck A, Verkerk PJ, Lasserre B, Marchetti M, Green T (2013) Mapping the distribution of forest ownership in Europe. EFI Technical Report 88. European Forest Institute

Pynnönen S, Paloniemi R, Hujala T (2018) Recognizing the interest of forest owners to combine nature-oriented and economic uses of forests. Small-Scale For 17:443-470

Seidl R, Scheelhaas M-J, Rammer W, Verkerk PJ (2014) Increasing forest disturbances in Europe and their impact on carbon storage. Nat Clim Change Lett 4:806-810

Shi J, Visschers CHM, Siegrist M (2015) Public perception of climate change: the importance of knowledge and cultural worldviews. Risk Anal 35:2183-2201

Shunk DH (2012) Learning theories: an educational perspective, 6th edn. Pearson, Boston

Steele J, Chandran RS, Grafton WN, Huebner CD, McGill DW (2006) Awareness and management of invasive plants among West Virginia Woodland owners. J Forest 104:248-253

Stoettner EM, Ní Dhubháin Á (2019) The social networks of Irish private forest owners: an exploratory study. For Policy Econ 99:68-76

Sun X, Sun C, Munn IA, Hussain A (2009) Knowledge of three regeneration programs and application behavior among Mississippi nonindustrial private forest landowners: a two-step sample selection approach. J For Econ 15:187-204

Swedish Forest Agency (SFA) (2014) Skogsstatistisk årsbok 2014 [Swedish Statistical Yearbook of Forestry]. The Swedish Forest Agency, Jönköping

Swedish Gov. Bill (2007/08:108) En skogspolitik i takt med tiden [A Forest Policy in Line with the Times]. Ministry of Agriculture, Stockholm
Swedish University of Agricultural Science (SLU) (2018) Forest Statistics 2018. SLU, Uppsala. https://www.slu.se/globalassets/ew/org/ centrb/rt/dokument/skogsdata/skogsdata_2018_webb.pdf

Thorn C, Bogner FX (2018) How environmental values predict acquisition of different cognitive knowledge types with regard to forest conservation. Sustainability-Basel 10:2188

Thorn S, Leverkus AB, Thorn CJ, Beudert B (2019) Education and knowledge determine preference for bark beetle control measures in El Salvador. J Environ Manag 232:138-144

Trivino M, Pohjanmies T, Mazziotta A, Juutinen A, Podkopaev D, Le Tortorec E et al (2017) Optimizing management to enhance multifunctionality in a boreal forest landscape. J Appl Ecol 54:61-70

Upton V, Ryan M, Heanue K, Ní Dhubháin Á (2019) The role of extension and forest characteristics in understanding the management decisions of new forest owners in Ireland. For Policy Econ 99:77-82

Weiss G, Lawrence A, Lidestav G, Feliciano D, Teppo H, Zuzana S et al (2019) Research trends: forest ownership in multiple perspectives. For Policy Econ 99:1-8

Publisher's Note Springer Nature remains neutral with regard to jurisdictional claims in published maps and institutional affiliations. 